\title{
Insurance and Risk Management of Foreign Trade Risks
}

\author{
by Yehuda Kahane*
}

\section{Introduction}

In most countries insurance of foreign risks is offered by government agencies which attempt to encourage and facilitate exports and international flow of goods and capital. The agencies are mainly concerned with the availability of credit to the exporters and with their need for collateral to guarantee such credit. The insurance arrangements are used merely as a technical means to attain these goals. It is, thus, only natural that certain principles which are observed in other forms of commercial insurance are often de-emphasized - if not completely disregarded - by these agencies (and by underwriters from the private sector who try to establish a foothold in this area).

The purpose of this paper is to examine insurance programs of foreign risks in the light of common insurance principles. The presentation is focused on the A-B-C of insurance, in an attempt to draw attention to the fact that insurance of foreign risks is often designed in a way which does not meet these basic principles. A taxonomy of foreign trade risks is presented in the Appendix - which deals with the identification and measurement of these risks - while the article concentrates on analyzing the means to control and finance them.

In a discussion of foreign risks it is worthwhile to first clarify and review the meaning of the term "risk". We often hear phrases such as: "this is too risky a project" or "this country is a bad risk". One meaning of these sentences is that the transaction (export, lending) will end up in a loss. Others interpret such phrases as meaning that there is a high expected loss, while still others mean that there is a high probability of loss. That is, the term "risk" is associated with "negative profitability".

This perception of "risk" does not coincide with the definition used in economic theory; economists distinguish between "risk" and "profitability". "Risk" is often measured as the chance of deviating from expected outcome, i.e., risk is identified with the term "surprise". A "high risk" situation is a situation where there is a small probability of a large loss! When exporters and foreign risk insurers talk about "bad risks" - they typically have the opposite idea in mind (i.e., the deal has a high probability to end up with a loss, or it is almost certain that the country will be unable to pay its debts).

\footnotetext{
* Academic Director, Erhard Insurance Center, Faculty of Management, Tel Aviv University, Israel.
} 


\section{Controlling foreign risks}

Unlike commercial banking, export credit is granted to those who need it, i.e., exporters who cannot supply reasonable collaterals to commercial lenders. Therefore, the foreign credit insurer is facing a high probability of loss, plus significant moral hazard problems.

The insured may apply risk control and risk financing techniques to deal with foreign risks.

\section{Risk control (by the insured)}

Risk control means handling risks by changing the probability of loss occurrence (frequency), and the probability distribution of the size of the loss (severity). It often proves to be more efficient than risk financing (and insurance). Risk may be controlled by:

1. Avoidance (foregoing the activity)

2. Risk assumption (retention)

3. Transfer

4. Prevention.

Avoidance - will be exercised only in extreme cases.

Assumption - is used when other methods are unavailable, insufficient or too expensive. It is recommended in cases where the probability of loss occurrence is relatively high, and the amount of loss is relatively low. In such cases the risk does not threaten the financial stability of the insured, and other means of handling (especially insurance) tend to be too expensive.

Transfer - could be a very useful technique for handling political risk. For example: joint ventures with local companies in the importing country rather than operating as a foreign company, using local financing (equity capital and borrowing), leasing rather than owning assets, etc.

Prevention - Unlike the risks of nature, many foreign risks are man-made and the best course is prevention (by those creating the risks). Unfortunately, the risks are often generated by governments and therefore are uncontrollable by individual exporters. Therefore, less presumptuous prevention should take place. Common prevention techniques used by exporters, and especially by investors in foreign countries are:

- Risk prevention techniques based on the matching of cash-flows in local currency with cash-flows in foreign exchange, in order to decrease the risk of incovertibility (strangely enough some countries limit the borrowing from other countries - thereby restricting the possibility of a better match between exports and imports)!

- Preserving the keys to certain technologies which are exported. This would serve as a barrier to expropriation.

- Strong dependence on external markets for the sale of end products.

- Using worldwide trademarks is useful to reduce the political benefits to expropriating governments.

- "Good citizenship" includes being an important employer or contributor to the local economy; operating jointly and/or in joint ownership with local businessmen; maintaining good relationships with authorities; avoiding criticism of local events, organizations or politics. 
- Operating through a firm registered in the country in which insurance/financing is abundant.

- Preserving the environment in the host country (avoiding noise, pollution, providing good pay and housing).

- Certain fields are more vulnerable than others to expropriation risk: e.g., industries which exploit major natural resources of the host countries. In case of investment in important plants - choosing a smaller size operation and avoiding over-capacity helps to increase dependency on such an operation, and reduces the risks.

- Using bilateral and multilateral barter agreements. From an economic point of view, this is an unpopular method since it means a breakdown of the monetary system and reintroduces inefficiencies and friction into the system of free trade. Barter also creates many problems from the insurers' point of view, especially since it is difficult to clearly define the amount of insured debt. Despite that, barter arrangements may sometime help to attain a better balance of a trade risk at the micro-economic level, and are, therefore, successfully used in practice.

\section{Risk financing}

Those risks that cannot be controlled may sometimes be contained through financing and insurance techniques.

- Certain monetary risks (inflation, interest rates, currency fluctuations) can be handled by employing immunization techniques (balancing portfolios, etc.).

- Another possibility is to use modern financial instruments such as forward contracts, currency options, interest rate options, swaps. (Note the superiority of hedging using options over the traditional use of forward arrangements.) Often, unfortunately, firms in LDCs cannot use these instruments due to local regulations prohibiting their use. Such countries have to offer insurance coverage, which may be more expensive and less effective.

- One form of risk financing is by means of insurance. Insurance may be used instead of, or in addition to, risk control. This instrument is treated in greater detail in the following section.

\section{Risk financing of foreign risks through insurance}

This section is focused on several central issues: Why is insurance used? Should it be used in its present form? What are the major difficulties involved - and what solutions may be offered?

\section{Why insurance?}

Insurance is transacted between two parties and has to simultaneously satisfy the needs of both the insured and the insurer. It is important to re-examine the motives of the two parties in order to be able to analyze and improve this financial instrument. A few explanations for the existence of insurance transactions are offered in the literature:

1. Differences in risk aversion, and the ability to diversify the insurer's portfolio ("the law of large numbers"). 


\section{Asymmetric information.}

3. Tax shifting.

Let us examine these explanations in the context of insurance of foreign trade risks.

a) Risk aversion and the law of large numbers: The insurance literature often defines an insurance transaction as the exchange of an uncertain situation, faced by the insured, with a non-risky one by means of paying a certain premium to an insurer who, in return, assumes the risk. The insurer is able to accept these risks because of his large capital and because of the "law of large numbers" which says that the distribution of the aggregated loss - faced by the insurer - differs from the distribution of each individual loss.

In order to benefit from the risk reduction effect stemming from diversification (the law of large numbers), the individual risks must not be positively correlated. This is not the case in foreign risks: these risks typically are strongly positively correlated, and even tend to have a catastrophic character. ${ }^{1}$ Thus, the elimination of the risk by diversification is quite limited - if possible at all.

b) Information: Other explanations for insurance transactions are based on the idea of asymmetric information (i.e., the insured does not hold the same information as the insurer). The superior data bases may be the strongest argument in favor of foreign trade risk insurance in general, and of having a governmental or public insurer handle the risk, in particular.

This strengh should be developed and emphasized by the members of the Berne Union. The members may develop their comparative advantage by improving their information systems and by developing better collection techniques. At present, the members collect and distribute information concerning individual companies and country risk, set ceilings on the amount of credit and determine permitted terms. ${ }^{2}$ The insurers - relying on their public sector backing - are exercising cartelistic power - which could not have been employed were the insurers operating on a competitive commercial basis. Moreover, in this way foreign risk insurers enjoy the advantage of taking concerted action against countries which do not meet their financial obligations. Such coordination would be much harder to achieve were each exporter obliged to deal with the problems individually.

The information argument is, however, less convincing than it appears to be at first glance; export credit insurance is a field in which the fear of moral hazard by the insured is quite substantial. Unlike other areas where governments supply catastrophe insurance coverage (e.g., natural disasters, or agricultural insurance), in the case of foreign trade risks the losses are man-made and the possibility of moral hazard is substantial.

\footnotetext{
${ }^{1}$ Catastrophes are typically defined in terms of the amount of loss. Foreign risks could be regarded as catastrophic from this point of view. Their size could often ruin not only the individual exporter/ importer but also large governmental agencies (due to the accumulation effect). Foreign risks are also catastrophic from another point of view - the existence of positive correlation between individual risks. In such cases the law of large numbers does not apply, i.e., the individual risks cannot be reduced by holding a diversified portfolio.

${ }^{2}$ Transactions are being rated according to the credit period, and according to the destination country (countries being grouped into classes A, B, C, D and X, the latter not eligible for credit).
} 
Since asymmetric information could be the major argument supporting government export credit insurance, I believe that the members of the Berne Union should develop their data bases and their ability to analyze risks. The effectiveness of the techniques presently used to analyze a country's individual exporters may be questioned: one has the feeling that collecting very detailed information on a specific customer may blur the picture, and leave the correlation with the entire economy hidden. More concerted effort should be devoted to the development of improved data bases and better analytic instruments.

c) Tax shifting: Another realistic (though little noted) explanation of the existence of insurance is the possibility of tax shifting: The insured is able to deduct the full premium from his taxable income. Since the insurance premium reflects expected future claims, he enjoys an earlier deduction of the cost of the risk. At the same time, the insurer is either un-taxed as a government entity, or enjoys the possibility of tax deferral through the reserving technique used. In other words, foreign risk insurance serves as an export subsidy through the tax system.

\section{What form of insurance should be used?}

The above discussion helps to focus on a number of points concerning the desirable foreign risk insurance:

a) Foreign risks are commercially uninsurable: From a theoretical point of view, most foreign risks violate the requirements of insurable risks and are, therefore, commercially uninsurable. Such risks have a catastrophic nature, and they are typically speculative risks (i.e., may result in profits rather than losses), whereas commercially insurable risks should always be "pure risks". In addition, other prerequisites of insurable risks are not met: the risks are often unmeasurable (unavailable statistics), they are subject to moral hazard, and are not necessarily random from the insured's point of view.

Like other risks of a catastrophic nature, which are commercially uninsurable (e.g., unemployment), most of the foreign risk coverage is, and could be, offered only by government and semi-government entities, and there is no norm for private insurance.

Although generally uninsurable, there are only certain types of coverage which are insurable by commercial insurers, e.g., those covering limited exposures (in monetary terms) and restricted to only certain perils, such as certain types of political risks, such as hijacking, confiscation or war risks in marine and aviation insurance, some commercial credit risks (short term post shipment financing, $\mathrm{L} / \mathrm{C}$, etc.; pre-shipment financing is riskier).

In fact, commercial insurers did operate in this area in Europe as early as the mid-19th century (a short lived experience...) and commercial insurers have been operating since the 1970's (e.g., certain Lloyds' underwriters, and large international insurers - some of them being present in this symposium).

b) Insurance should discourage moral hazard. The existence of an insurance policy usually creates the well known situation of moral hazard. That is, the availability of insurance makes the insured less concerned with the occurrence of the loss, so that the probability of loss and its size may increase, since the insured may expose himself to riskier situations than he would if he didn't carry insurance, in an attempt to maximize his profits while disregarding the risk (e.g., deposit insurance for the saving and loan association encouraged them take very risky positions). All foreign risk insurance programs that we have examined attempt to discourage 
moral hazard by supplying only partial coverage, by having co-insurance arrangements (the insured sharing the loss with the insurer) and by waiting period arrangements.

Besides moral hazard, insurance contracts often tend to create situations of adverse selection, i.e., the insureds tend to cover only the "bad" risks. All contracts that we have examined avoid this problem by requiring that the insured cover all his credit transactions (or by charging a much higher premium when insuring sales to only certain customers), and by placing other limitations (e.g., that the loss is beyond the insured's control). In addition, most insurers place credit quotas on each exporter, importer, country, etc. to help mitigate this effect. Credit can be denied to the firms which abused the system in the past. A good information system is needed for that purpose.

c) Cartel power in information. Insurers benefit from having superior information. Foreign risk insurers should expand their information bases, both at the inception of a transactions and when an importing country faces difficulties.

The importance of the public sector in LDCs is usually quite outstanding. This fact, plus their typical budgetary problems and often unusual procedures used, make these countries vulnerable to changes of policy which become effective with a "push of a button". The fact that most foreign risk insurers are also government agencies (of the developed countries) may sometimes help to reduce this type of risk, by improving the ability to use concerted action in such situations.

d) Risk sharing. Commercial insurance typically uses international diversification (through reinsurance) to reduce risks which are perceived as catastrophic in a local arena. This technique is not used by government entities. In other words, each economy continues to bear the entire burden of risk.

The inability to achieve international diversification, due to the lack of reinsurance mechanisms, may be corrected by forming some sort of an international fund to serve as the reinsurer of all these national programs. The first step in this direction would be a clearing house to offset the risks of individual export and import of each specific country. Such an international agency would enable the handling of insurance and financing problems simultaneousely, and may also be involved in refinancing the credit granted by LDCs. An international fund may determine country quotas, and could serve as an excess-of-loss or stop-loss reinsurer. Alternatively, each insurer should be active in financing and insuring both suppliers' and buyers' credit to each country, rather that the traditional specialization in one type (usually suppliers credit).

e) International subsidies: The common belief is that export credit insurance (within the limits of international agreements) subsidizes exporters. Despite this view, the governments of developed countries, may discover that they are in practice subsidizing the LDCs (by enabling them to import goods and services at subsidized prices). Similarly, the governments and the (few) export credit insurers in the LDCs are subsidizing the developed economies. The policy of many LDCs to grant investment incentives is only another side of the coin. ${ }^{3}$

${ }^{3}$ In some cases these incentives do not encourage the foreign investor but rather subsidize the government of the exporting nation (e.g., a U.S. investor in Israel is entitled to a lower tax rate in Israel, but will have to pay the difference between this rate and the full U.S. rate to the U.S. government). 
In other commercial insurance lines such subsidization is avoided because of the ability to subrogate losses. Subrogation is impractical for most types of political risks (e.g., confiscation) and sometimes for commercial risks as well. In such cases, potential retaliation could serve as a better weapon and for that purpose it is important to increase the proportion of international trade which is handled through barter and trade agreements (where the cashflows are more or less balanced at any point, and where goods could be used as collateral against confiscated goods).

f) Ratemaking and actuarial considerations. As a rule, an insurance policy is not intended to turn a bad business into a good one. The financing and insurance should be supplied at a reasonable cost to the exporter (i.e., the availability of credit and insurance is not the unique goal). If the premium set by the government bodies does not reflect the true economic cost of the risk (which is difficult to assess ex-ante) the government is either subsidizing or penalizing the insured firm (besides the subsidy granted through the tax system, which has been discussed above).

In general, risk financing through insurance is often criticised for being "too expensive" due to "loading" of expenses (and profit) on the premium. It should, however, be remembered that the insurance is often needed as a collateral for credit, i.e., insurance is bought because the bank requires it, not necessarily because it is desirable from the insured's point of view. In other words, the true cost of insurance from the exporter's (borrower) point of view is lower than the premium; the reduction of the interest on borrowing should be used to offset the cost of insurance. The net effect could be a profit.

Sophisticated actuarial techniques should be established for ratemaking. This involves the building of useful data bases and information systems. Rate structure should be detailed enough to distinguish between different risks. However, the rate structure should also be simple. Is the amount of sale, or credit, the appropriate exposure unit? Should there be a bonus/malus or experience rating? Should rates be additive or multiplicative rating? Should rates represent present value of claims? All these question (and others) should be analyzed actuarially.

Appropriate reserving techniques like those used in commercial insurance (unearned premium reserves, loss reserves, etc.) should also be developed in foreign risk. Due to the specific nature of the business, a certain percentage of each year's premium should be accumulated in a special reserve for extraordinary risks (such as earthquake insurance).

\section{Concluding remarks}

The goal of this presentation was to examine insurance of foreign risks according to common principles of commercial insurance. This examination leads to the conclusion that except for a few cases, these risks are commercially uninsurable, and should be handled, if at all, through the public sector.

The insurance of foreign risks lacks the reinsurance instrument, which is so useful in commercial insurance. This creates situations of subsidization: the developed countries subsidizing the LDCs - and not their exporters - as may be commonly believed, in addition to the subsidization through the tax system, which is often unnoticed. It is suggested that an international fund be created to serve as an international reinsurer. 
This special line of insurance relies on the effective collection and use of information by the insurer. Creative efforts should be made in this direction, where the government insurers may exercise cartel power.

\section{Appendix: the identification and measurement of foreign risks}

This appendix outlines the key elements of foreign risks, and briefly summarizes the exposures, perils and the parameters affecting the assessment of the risk.

\section{The exposures and perils}

Exposures are typically classified according to the duration of the required financing, according to the potential losses, and according to the perils capable of generating the losses.

\section{The potential losses}

- Direct loss of property and money

- Indirect losses (delays, loss of market)

- Unexpected deviations from forecast (modifications of order, the temporary need to change scale of production)

- Incovertibility of money.

Note: Losses may be direct and physical, but may sometimes be connected to rumours, libel, etc.

\section{The perils}

Perils are often roughly classified under the headings: "political" or "commercial". "Political" perils are those which can be only slightly affected by the individual exporter/importer. It should be noted that this distinction is often artificial, and sometimes even misleading; political and commercial perils may be closely related: a political change may affect the economic environment of the individual firm (or industry), and may, thus, create what appears to be a commercial risk. A political move in a developed country may trigger what appears to be a commercial risk of a less developed country.

Keeping this important reservation in mind, we follow the traditional distinction between "political" and "commercial" perils.

Perils of a political nature: non-payment or delayed payment or losses due to:

- currency exchange regulations and problems of convertibility of local currency

- extra duties, taxes

- regulations preventing transfer of money (interest, profits, repayment of loans or realized value of investments) due to balance of payments problems.

- cancellation or refusal to issue import/export license, changes in import/export regulations, boycotts, embargoes

- moratorium on borrowing 
- inability to collect from a government agency (this creates special problems due to the inability to litigate or force it into liquidation - "The Risk of the Sovereign").

- product liability rules and the possibility of being sued for punitive damages, as impediments to export to certain countries

- strikes (political)

- war risks

- civil war, revolution, insurrection, riots, acts of fanatism, etc.

- terrorism, hijacking, kidnapping, arson, sabotage

- nationalization, confiscation, expropriation (also when goods are embargoed by a third country, while being transported through it)

Perils of a commercial nature: non-payment or delayed payment for goods and services supplied, due to:

- non-shipment (pre-shipment risk), cancellation of order prior to shipment

- breach of contract (by importer or exporter)

- commercial disputes due to delays, failure to meet specifications, quality problems, etc. (This risk may be higher in the developed countries due to moral hazard.)

- problems arising from fraud or from forged documents

- buyer's financial difficulties or bankruptcy

- exchange rate risk (in the original currency, and when insured not in the original currency)

- inflation

\section{Classification of perils by duration and terms of financing}

- Pre-shipment financing (to manufacturer or exporter)

- Post-shipment financing

- Export of consumer goods and services and raw material (short-term credit)

- Export of durable goods, equipment, etc. (medium-term credit)

- Long-term contracts (construction projects, etc.)

- Overseas operations and capital investments

\section{The assessment of risk}

Risk is assessed by considering general factors (related to the economy/industry) and specific factors (related to the firm or the specific transaction).

\section{General factors}

Factors depending on the economic environment (in the importing/exporting country):

- internal/external debt, borrowing and its terms, a country's credit rating

- balance of payments and its trend

- growth acceleration and deceleration

- managerial skill, government competence

- resources: energy, water, food, minerals, labour, education

- availability and cost of labour, the power of unions

- vulnerability to natural catastrophes such as weather conditions, storms, flood, earthquakes, etc.

- diversification of economy vs. dependence on a specific product or market 
- new technologies enabling the manufacture of substitutes for the country's main resources, or market changes for these products

- income distribution

- specific problems creating strains on the budget (defense)

- role of government in the economy: restrictions and regulations

- trade policies

- taxation and tax evasion

- the sophistication of the capital markets, avalability of funds (even state-owned commercial banks may give priority to better risks...)

- currency, inflation

- transportation (ports, bridges, etc.)

Factors related to the social, cultural and political environment:

- balance, imbalance or polarization of the political/ethnic/cultural structure

- power struggles

- international relations and conflicts (border disputes, enmity)

- global strategic importance (geographic, resources)

- dependence on external support

- agents of change (motives, ways and means, timing)

- government philosophy regarding freedom, control, domestication

- history, tradition

- discontented groups and their power (armed?) and methods of operation

\section{Specific factors}

a) Factors depending on the specific transaction or project:

- terms of payment and terms of credit (pre-shipment, post-shipment, sight L/C, confirmed $\mathrm{L} / \mathrm{C}$, consignment, etc.), credit period

- pre-shipment financing is very important in LDCs.

- feasibility

- experience of all parties in this type of business.

b) Factors depending on the individual firm (both exporter and importer)

- know-how and ability to perform (capacity)

- its actions (competition, exploitation of natural resources, employment policy, "good citizenship", etc.)

- public image and declared attitudes

- nature of the firm (partnership, private, public, government)

- financial standing and ability to perform even when forecasts are not realized

- past record

- technology, quality control

- dependence on government licensing, etc.

- correlation with rest of the economy 
The goal of the analysis

Gathering information about the foreign arena (relevant regulations, unions, political institutions, etc.) prior to the beginning of any activity, could prevent major problems later:

- identifying the event that could affect the activity

- estimate the likelihood of occurrence and its timing

- estimate vulnerability (risk?)

\section{Identification and measurement of risk}

Difficulties in identification and measurement

- In general, it is difficult to identify the risks. Therefore evaluations from many sources, including local experts, are necessary

- Uncertainty with regard to: what (whether, when, where) may happen

- Major problems in quantifying risks

- Severe problems in measuring correlation among risks

- When dealing with political factors, strong positive correlation among individual risks is usually expected. However, sometimes only certain industries or firms are affected.

- The possibility of highly unexpected events (i.e., "high risk")

Losses may be deliberately caused by:

- property damages and "personal" damages - loss of goodwill, etc.

- local government (de jure or de facto)

- foreign government

- political parties

- political groups

- competitors (domestic or foreign)

- suppliers, customers

- partners, personnel

- neighbours

The losses may be motivated by:

- political goals (e.g., the desire to control industry, local patriotism, desire to change environment or society, wish to obtain funds, objection to certain activities, intent to create anarchy, blackmail, etc.)

- hostility due to disturbance (e.g., competitors, neighbours, personal reasons, etc.)

- opposition towards ideology or actions 